\title{
Atomic Layer Deposition of Gold Metal
}

Matthew B. E. Griffiths, Peter J. Pallister, David J. Mandia, and Seán T. Barry ${ }^{*}$

Department of Chemistry, Carleton University, 1125 Colonel By Drive, Ottawa, Ontario, K1S 5B6, Canada.

\section{Supplementary Material}

\section{Precursor Synthesis}

All manipulations were performed with rigorous exclusion of air using an Mbraun Labmaster 130 glovebox, Schlenk techniques, and N2 ( $\geq 99.998)$ gas. NMR analysis was performed using a $300 \mathrm{MHz}$ Bruker Avance spectrometer. $\mathrm{HAuCl}_{4} \times \mathrm{H}_{2} \mathrm{O}$ (49.9 weight \% Au) was purchased from Strem Chemicals and used as received. Trimethylphosphine was also purchased from Strem Chemicals as $5 \mathrm{~g}$ in an ampoule, and was diluted to $1.31 \mathrm{M}$ solution in toluene and then stored in an $\mathrm{N}_{2}$-atmosphere glovebox in a teflon screwcap bottle. MeLi (1.6 M in diethyl ether) was purchased from Sigma-Aldrich as 4 x $25 \mathrm{~mL}$ bottles packaged under nitrogen in SureSeal septa and used as received. Anhydrous dichloromethane, tetrahydrothiophene, and methyl iodide were purchased from Sigma-Aldrich and was used as received. Diethyl ether was purified using an Mbraun Solvent Purification System.

Tetrahydrothiophenegold(I) chloride: $\mathrm{HAuCl}_{4} \cdot \mathrm{xH}_{2} \mathrm{O}$ (49.9 weight \% $\mathrm{Au}, 20.45 \mathrm{mmol}$ ) was dissolved in $120 \mathrm{~mL}$ of 5:1 EtOH : $\mathrm{H}_{2} \mathrm{O}$ in a $400 \mathrm{~mL}$ beaker. $4.2 \mathrm{~mL}$ (47.64 mmol) of tetrahydrothiophene (THT) was added dropwise causing the precipitation of a flocculent white solid. This was stirred for $1 \mathrm{hr}$ and then filtered, washed sequentially with 3 x $20 \mathrm{~mL}$ of ethanol, $3 \times 20 \mathrm{~mL}$ of diethyl ether, and then dried under high vacuum for 12 hours. The yield was $90-$ $98 \%$, based on multiple trials (typical mass $\approx 6.5 \mathrm{~g}$ ). 
Trimethylphosphinogold(I) chloride: In a glove box, dry tetrahydrothiophenegold(I) chloride (6.55 g, $20.4 \mathrm{mmol})$ was dissolved in a minimum of dichloromethane in a $250 \mathrm{~mL}$ Schlenk flask. Dilute $\mathrm{PMe}_{3}(15.5 \mathrm{~mL}, 1.31 \mathrm{M}$ in toluene, $20.4 \mathrm{mmol})$ was added drop-wise, and the reaction was stirred for 1 hour. In a fume hood, this solution was filtered through a medium frit, washing with dichloromethane to pass all of the product. The resulting solution was left in a fume hood overnight to evaporate, resulting in the formation of a bright white crystalline solid. Yield $=6.20$ g, $99 \% .{ }^{1} \mathrm{H}-\mathrm{NMR}\left(300 \mathrm{MHz}, \mathrm{CDCl}_{3}\right): \delta 1.62\left(\mathrm{~d},\left(\mathrm{PMe}_{3}\right)\right),{ }^{2} \mathrm{~J}_{\mathrm{H}-\mathrm{P}}=11.4 \mathrm{~Hz}$.

Trimethylphosphinotrimethylgold(III): $5.533 \mathrm{~g}(18 \mathrm{mmol})$ of $\left(\mathrm{PMe}_{3}\right) \mathrm{AuCl}$ was placed in a $500 \mathrm{~mL}$ Schlenk flask along with a stir bar and was then dried under high vacuum for 2 hours. Meanwhile, a $100 \mathrm{~mL}$ dropping funnel was flame dried under high vacuum, then cooled to room temperature under vacuum. Both Schlenk flask and dropping funnel were then backfilled with $\mathrm{N}_{2}$. The $\left(\mathrm{PMe}_{3}\right) \mathrm{AuCl}$ was suspended in $300 \mathrm{~mL}$ of dry $\mathrm{Et}_{2} \mathrm{O}$, and the dropping funnel was then attached under a stream of $\mathrm{N}_{2}$ from both flask and funnel. The top of the dropping funnel was then fitted with a dry rubber septum, flowing nitrogen from the Schlenk arm of the $500 \mathrm{~mL}$ flask. With the apparatus assembled, the suspension was cooled to $-78^{\circ} \mathrm{C}$ in a dry ice / isopropanol bath.

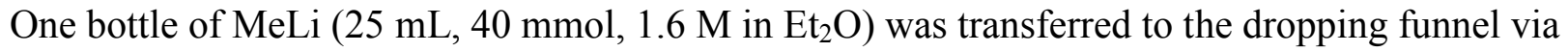
cannula using a slight vacuum assist from the Schlenk arm. The Schlenk arm was only slightly cracked to vacuum, and then closed again. This was repeated until all the MeLi has been transferred. Care was taken not to keep the system under active vacuum since this was found to cause MeLi to precipitate in the dropping funnel. An anti-backflow bubbler was used on the nitrogen line to ensure that no air could enter the system during the vacuum-assist. 
Once transferred, the cannula was removed, and MeLi solution was added very slowly drop-wise at a rate of 1 drop every 6-8 seconds. A very slow addition was key to a high yield since the intermediate formed was very thermally unstable. A total addition time of 50-60 min was ideal. Once all the MeLi was added, the funnel was rinsed with $20 \mathrm{~mL}$ of dry diethyl ether, which was then added dropwise to the stirring solution. By this point, the suspension often appeared yellow to green in colour. This suspension was stirred for 2 hours after completion of MeLi addition at $78^{\circ} \mathrm{C}$.

MeI (1.91 mL, $30.6 \mathrm{mmol})$ was then added very slowly dropwise over $10 \mathrm{~min}$, and the reaction was stirred for a further 2 hours at $-78^{\circ} \mathrm{C}$. The colour of the suspension usually returned to white at this point, but yellow or grey was also observed.

The reaction was allowed to warm to room temperature over 1 hour, and was then cooled in an ice bath. $40 \mathrm{~mL}$ of distilled water was added to the funnel, and this was then added dropwise to the stirring suspension at an initial rate of one drop every 10 seconds. Colour change or consistency change of the reaction warranted stopping addition and allowing for the reaction to subside before continuing again. When addition was done too quickly, the flask would turn dark purple. If done correctly, a slight purple to clear ethereal solution formed above an aqueous solution, generally about 30 minutes of drop-wise addition. Gradual darkening of the solution was normal.

The ethereal layer was separated using a separatory funnel without shaking, and dried over excess $\mathrm{MgSO}_{4}$ which served as both a drying agent and a nanoparticle sequestering agent. The solution was filtered and dried on a rotary evaporator yielding a colourless liquid. If this liquid was contaminated by $\left(\mathrm{PMe}_{3} \mathrm{AuMe}\right)$, then an additional purification step was required before 
proceeding. $\left(\mathrm{PMe}_{3} \mathrm{AuMe}\right): 1 \mathrm{H}-\mathrm{NMR}\left(300 \mathrm{MHz}, \mathrm{CDCl}_{3}\right): \delta 1.43\left(\mathrm{~d}, 9 \mathrm{H},\left(\mathrm{PMe}_{3}\right),{ }^{2} \mathrm{~J}_{\mathrm{H}-\mathrm{P}}=8.8 \mathrm{~Hz}\right)$, $\delta 0.33\left(\mathrm{~d}, 3 \mathrm{H},\left(\mathrm{Au}\left(\mathrm{CH}_{3}\right)\right),{ }^{3} \mathrm{~J}_{\mathrm{H}-\mathrm{P}}=8.4 \mathrm{~Hz}\right)$.

Purification Step: If $\left(\mathrm{PMe}_{3}\right) \mathrm{AuCH}_{3}$ was observed by NMR dissolved in the product, the mixture was then dissolved in 3 volume equivalents of neat methyl iodide and stirred in a sealed flask for 6 hours. The MeI was then evaporated, leaving a mixture of the product, $\left(\mathrm{PMe}_{3}\right) \mathrm{AuMe}_{3}$, and (PMe)AuI, the latter of which is non-volatile.

This liquid (or purified / recycled material) was purified by simple vacuum distillation $\left(80^{\circ} \mathrm{C}\right.$, $100 \mathrm{mTorr}$ ) using a cold water condenser and an ice-cooled receiving flask. The product was dislodged from the condenser periodically by gentle heating with a heat gun or Bunsen burner until it liquified and flowed again into the receiving flask. Yield $=5.30 \mathrm{~g},(93 \%)$. m.p. $=22^{\circ} \mathrm{C}$.

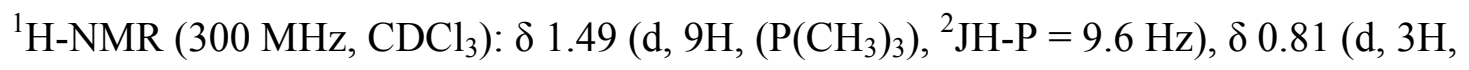
$\left.\left(\mathrm{Au}\left(\mathrm{CH}_{3}\right)_{2}\left(\mathrm{CH}_{3}\right)\right),{ }^{3} \mathrm{~J}_{\mathrm{H}-\mathrm{P}(\text { trans })}=9.6 \mathrm{~Hz}\right), \delta 0.09\left(\mathrm{~d}, 6 \mathrm{H},\left(\mathrm{Au}\left(\mathrm{CH}_{3}\right)_{2}\left(\mathrm{CH}_{3}\right)\right),{ }^{3} \mathrm{~J}_{\mathrm{H}-\mathrm{P}(\mathrm{cis})}=7.6 \mathrm{~Hz}\right),{ }^{13} \mathrm{C}-$ $\left\{{ }^{1} \mathrm{H}\right\}$-NMR $\left(75 \mathrm{MHz}, \mathrm{CDCl}_{3}\right): \delta 12.02\left(\mathrm{~d}, \mathrm{P}\left(\mathrm{CH}_{3}\right)_{3},{ }^{1} \mathrm{~J}_{\mathrm{C}-\mathrm{P}}=28.9 \mathrm{~Hz}\right), \delta 10.87(\mathrm{~d}$, $\left.\left(\mathrm{Au}\left(\mathrm{CH}_{3}\right)_{2}\left(\mathrm{CH}_{3}\right)\right),{ }^{2} \mathrm{~J}_{\mathrm{C}-\mathrm{P}(\text { trans })}=133.0 \mathrm{~Hz}\right), \delta 6.46\left(\mathrm{~d},\left(\mathrm{Au}\left(\mathrm{CH}_{3}\right)_{2}\left(\mathrm{CH}_{3}\right)\right),{ }^{2} \mathrm{~J}_{\mathrm{C}-\mathrm{P}(\text { cis })}=28.9 \mathrm{~Hz}\right) .{ }^{31} \mathrm{P}-$ $\left\{{ }^{1} \mathrm{H}\right\}-\mathrm{NMR}\left(121 \mathrm{MHz}, \mathrm{CDCl}_{3}\right): \delta-9.75\left(\mathrm{P}^{\left.\left(\mathrm{CH}_{3}\right)\right)}\right.$.

Thermogravimetric (TG) Characterization Experimental: In a typical experiment, $\sim 20 \mathrm{mg}$ of $\mathbf{1}$ was loaded in a platinum pan which was hung on the microbalance arm of a TA Instruments Q500 TGA, which is housed in an inert atmosphere MBraun glovebox. All experiments were purged by nitrogen gas. In the ramp experiment (Supplemental Figure 1a), a ramp rate of $10^{\circ} \mathrm{C} / \mathrm{min}$ was employed from room temperature to $500^{\circ} \mathrm{C}$. For the isothermal experiment (Supplemental Figure 1b), the temperature was ramped automatically to a set-point of $65^{\circ} \mathrm{C}$ and held at this temperature for 175 minutes. 

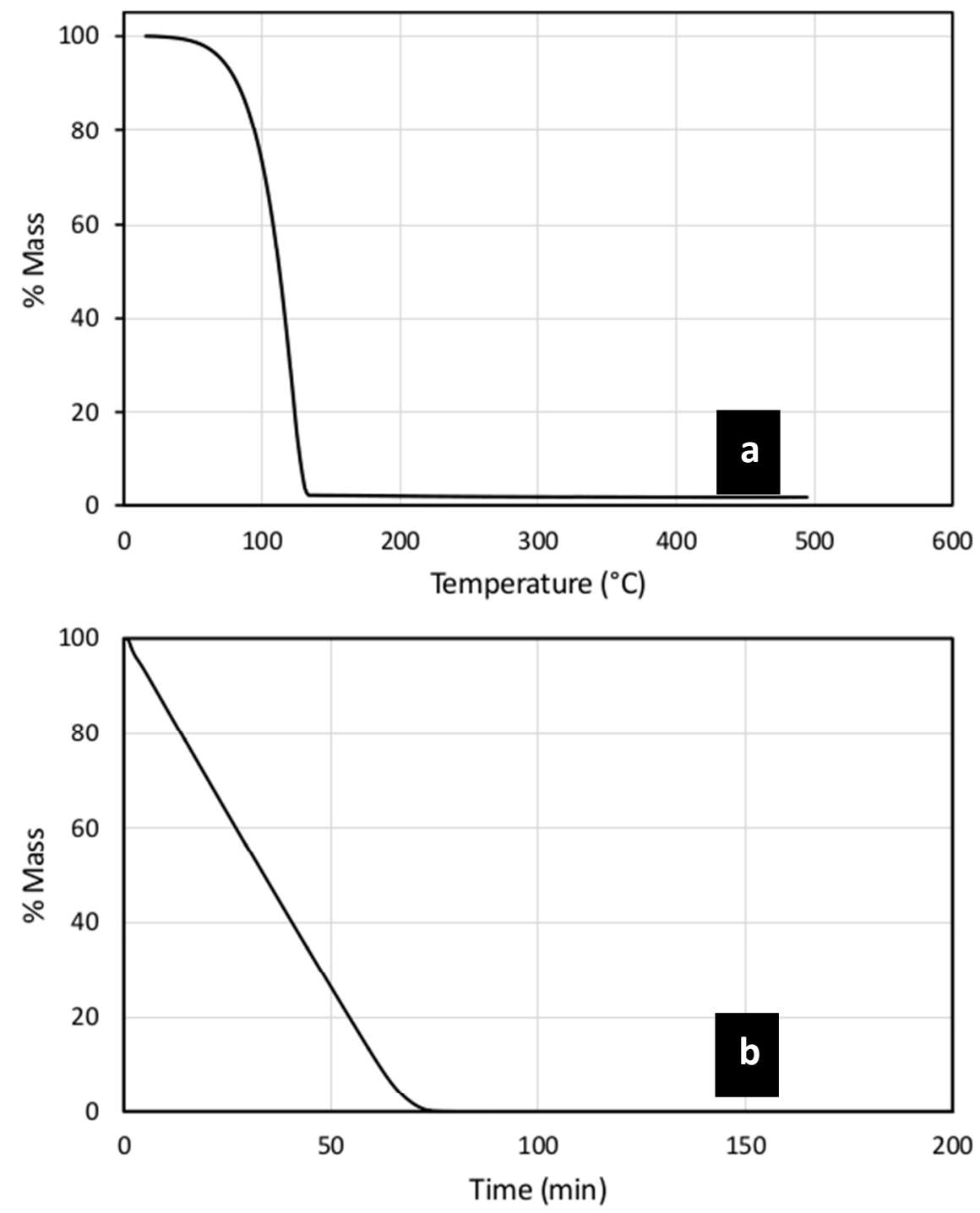

Supplemental Figure 1. The thermogravimetric (TG) traces for 1. a) The standard ramp TG with a ramp rate of $10^{\circ} \mathrm{C} / \mathrm{min}$; b) the isothermal TG holding 1 at $65^{\circ} \mathrm{C}$. 
Vapor Pressure Determination Experimental: To calculate a Langmuir vapor pressure curve for $\mathbf{1}, \sim 50 \mathrm{mg}$ of 1 was loaded in a platinum pan which was hung on the microbalance arm of a TA Instruments Q500 TGA, which is housed in an inert atmosphere MBraun glovebox. A temperature program was run such that the temperature was ramped by $10^{\circ} \mathrm{C}$ and then held isothermally for 10 minutes. This was repeated from room temperature to $400^{\circ} \mathrm{C}$. The slope of the linear weight loss per unit time at each isothermal step was calculated and expressed with respect to the area of the pan. This was graphed on a logarithmic scale against $1 /$ temperature to extract a relationship for mass delivery by temperature (Supplemental Figure 2). A known method $^{1}$ was used to calculate the Langmuir expression for vapor pressure.

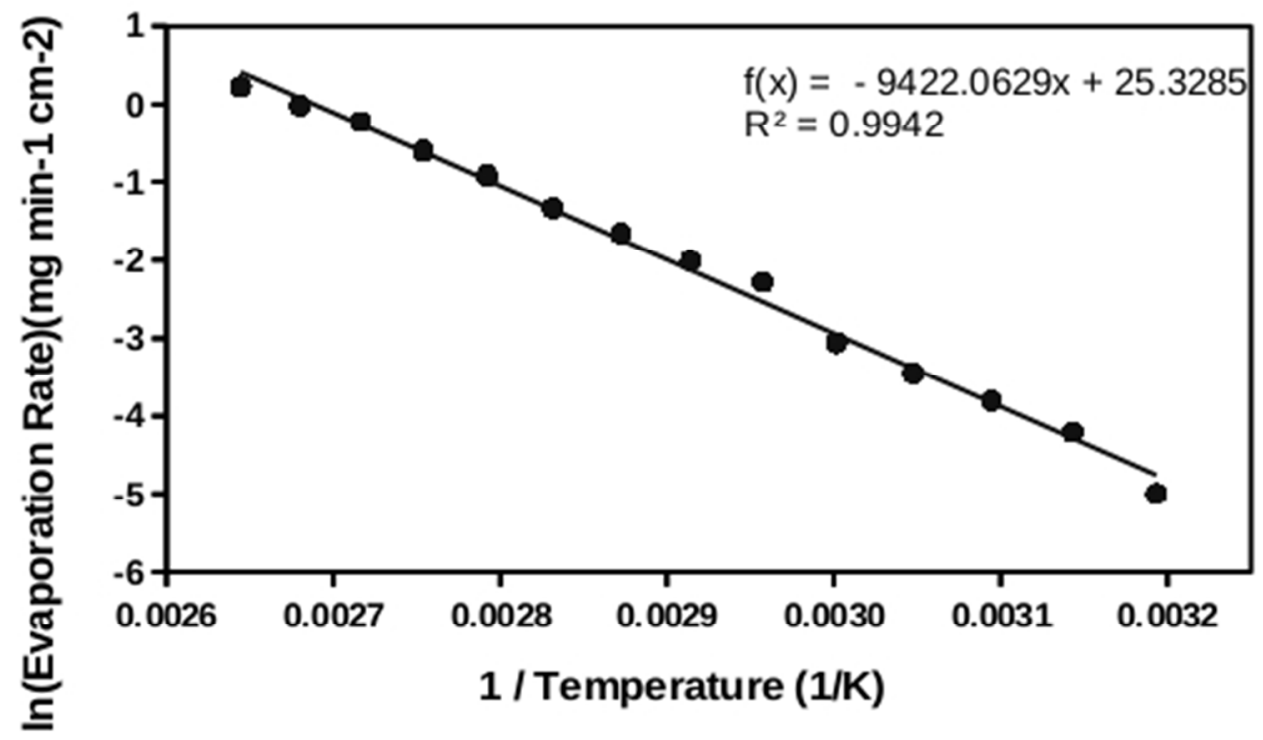

Supplemental Figure 2. The evaporation rate for 1. The inset is the fitted linear regression and coefficient of determination for the fit.

\footnotetext{
${ }^{1}$ Kunte, G. V.; Shivashankar, S. A.; Umarji, A. M. Thermogravimetric evaluation of the suitability of precursors for MOCVD Meas. Sci. Technol. 2008, 19, 025704.
} 
Thin Film Characterization Experimental: Typically, the gold films were deposited using 100 cycles using $4 \mathrm{~s}$ pulses of $\mathbf{1}, 14 \mathrm{~s}$ pulses of $\mathrm{O}_{2}$ plasma, and $0.1 \mathrm{~s}$ pulses of water with $10 \mathrm{~s}$ nitrogen gases purges between each step. These films were imaged using a Tescan Vega-II XMU Variable Pressure Scanning Electron Microscope with $20 \mathrm{keV}$ potential (Supplemental Figure 3). The films appeared well connected and uniform. Attempts at characterizing the resistivity were unsuccessful due to poor adhesion of the gold metal film on glass and silicon/ $/ \mathrm{SiO}_{2}$ substrates. XPS spectra were collected in the analysis chamber of a Specs/RHK multi-technique ultrahigh vacuum system using a Phoibos 100 SCD power supply, hemispherical analyzer, and detector. Whenever possible, the sample being analyzed was electrically grounded. An XR-50 X-ray source containing an $\mathrm{Al}$ anode (400 W) was used in this study (14.26 keV Al Ka source), and analyses were performed within a base pressure range of $7 \times 10-10-1 \times 10-9$ Torr. Survey (Supplemental Figure 4) and high-resolution scans of the as-deposited gold films were collected using SpecsLab2 software, and post-processed and deconvoluted using CasaXPS. Highresolution spectra were fitted to a Shirley background and fitted using the appropriate Scofieldbased factors for photoelectron cross-section. The film appears to have a nucleation delay of 96 cycles according to the growth per cycle fit (Supplemental Figure 5), and this is presently under scrutiny in our lab.

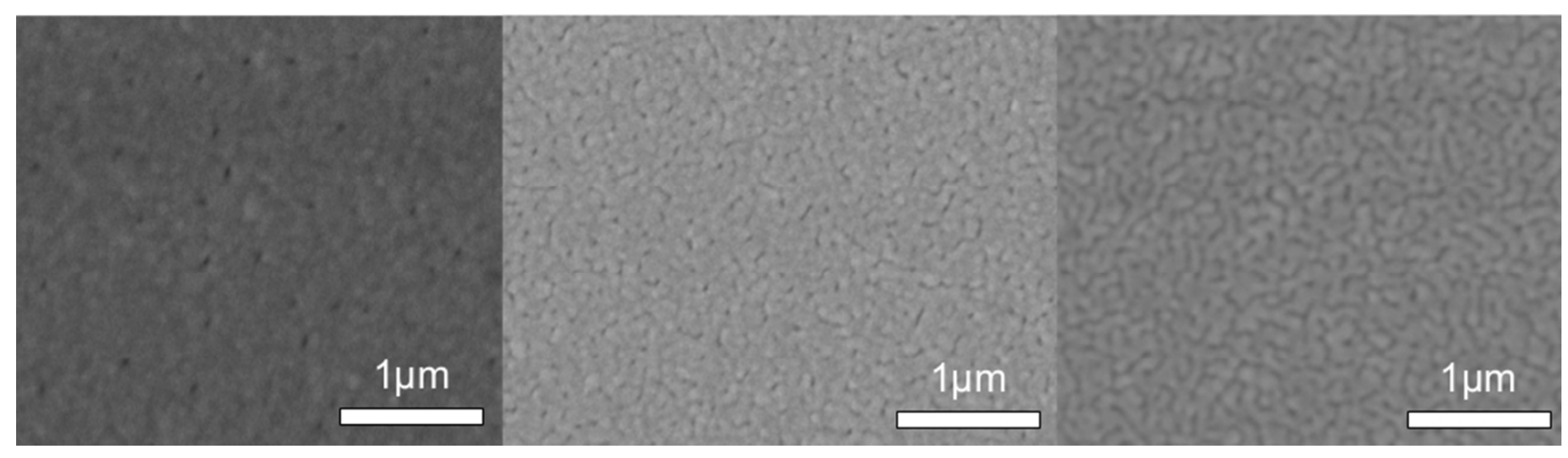


Supplemental Figure 3. Scanning electron microscopy images of gold metal films deposited by 1. Each of these independent depositions were comprised of 1000 atomic layer deposition cycles using $4 \mathrm{~s}$ pulses of $\mathbf{1}, 14 \mathrm{~s}$ pulses of $\mathrm{O}_{2}$ plasma, and $0.1 \mathrm{~s}$ pulses of water with $10 \mathrm{~s}$ nitrogen gases purges between each step.

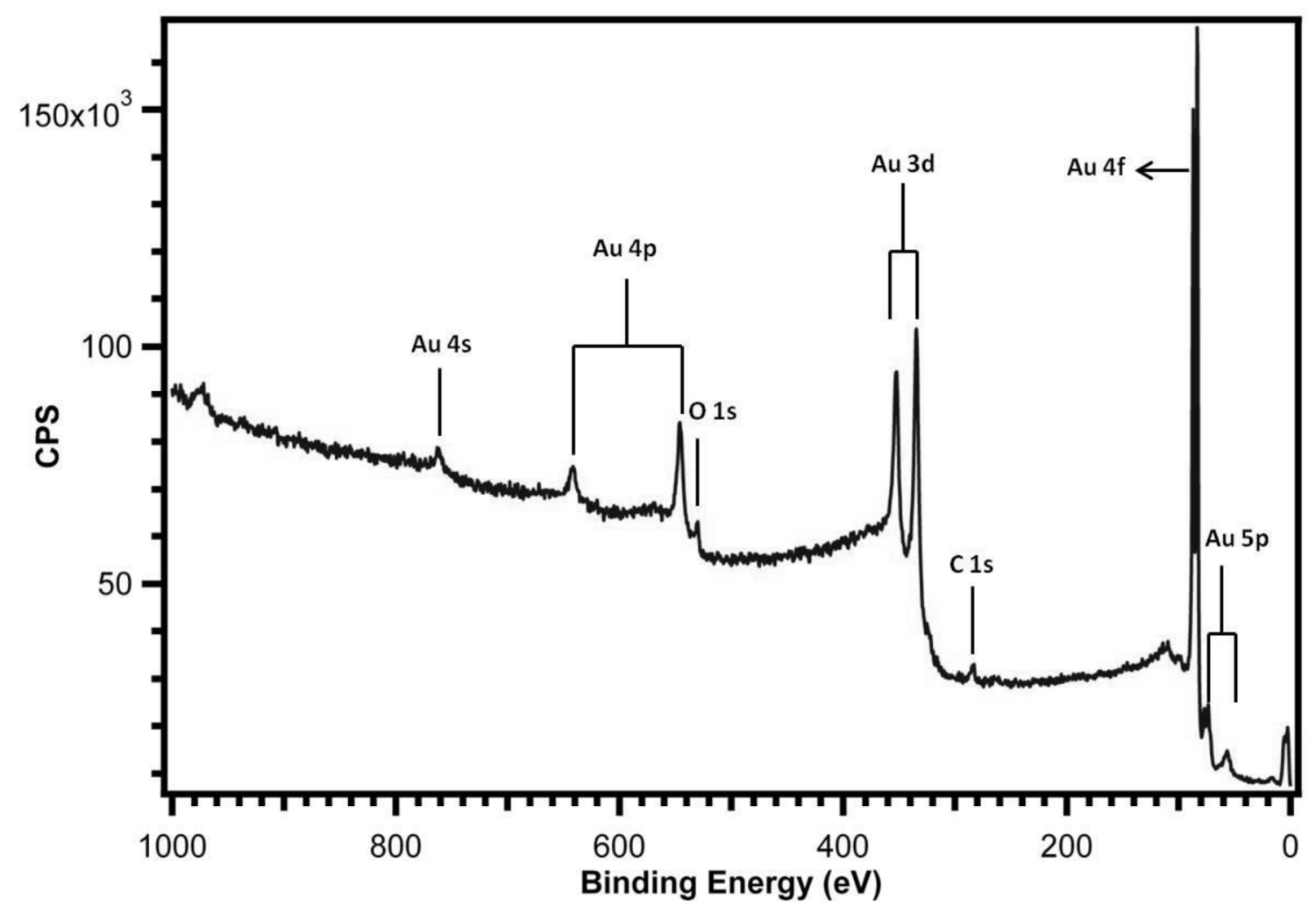

Supplemental Figure 4. An XPS survey spectrum of a gold film deposited on a $\operatorname{Si}(100)$ substrate using $4 \mathrm{~s}$ pulses of $\mathbf{1}, 14 \mathrm{~s}$ pulses of $\mathrm{O}_{2}$ plasma, and $0.1 \mathrm{~s}$ pulses of water with $10 \mathrm{~s}$ nitrogen gases purges between each step. 


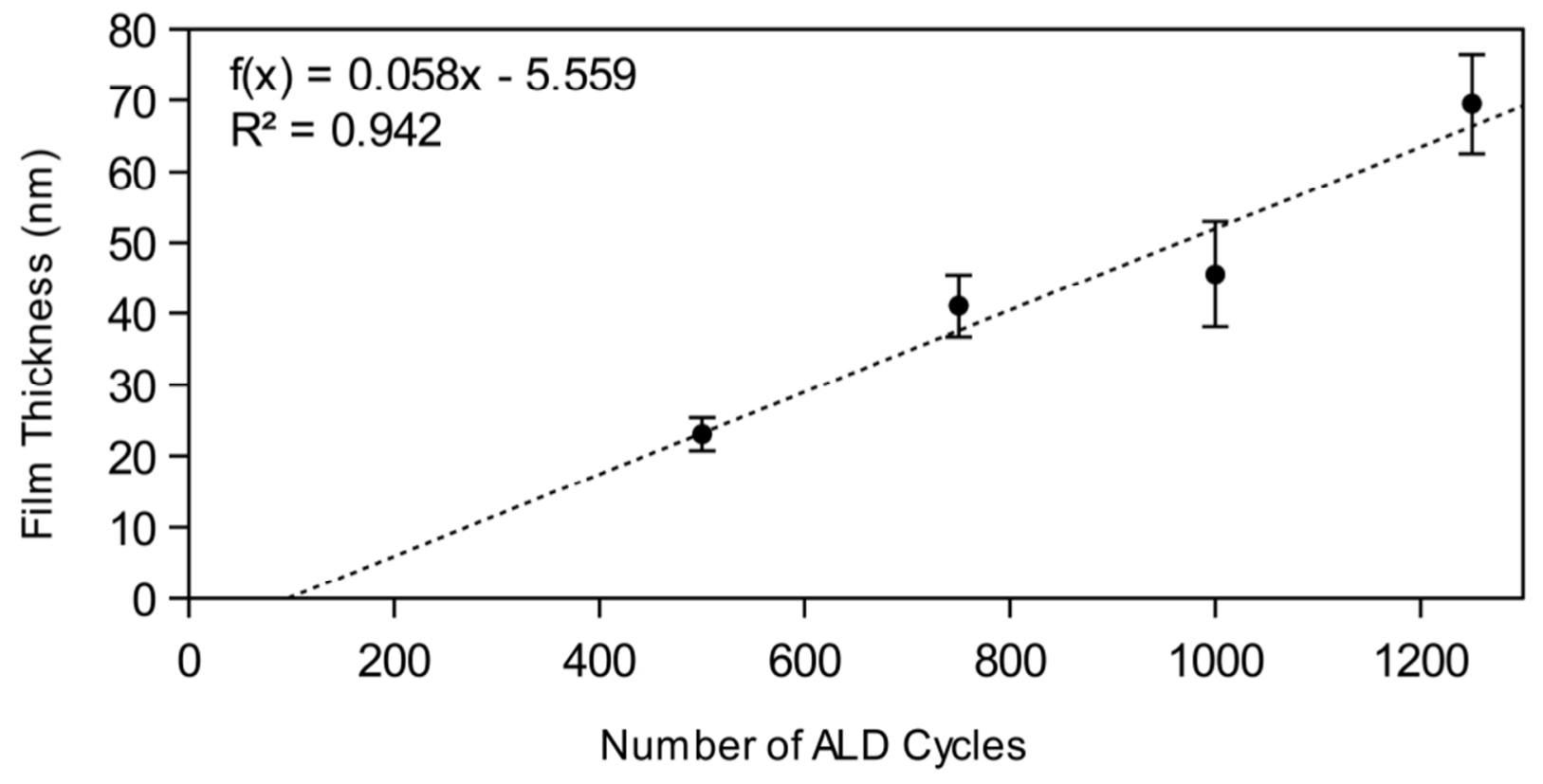

Supplemental Figure 5. A graph of the growth rate as a function of cycle number. 